\title{
Effect of Initial Size and Shape Importance on Masse Transfer during Convective Drying
}

\author{
Kondia Honoré Ouoba ${ }^{1 *}$, François Zougmore ${ }^{1}$, Hélène Desmorieux ${ }^{2}$ \\ ${ }^{1}$ Laboratoire des Matériaux et Environnement (LA.M.E.), Ecole Doctorale Sciences et Technologies (EDST), Université Ouaga I \\ Pr Joseph KI-ZERBO, Burkina Faso \\ ${ }^{2}$ Laboratoire d'Automatique et de Génie des Procédés, LAGEP, UMR CNRS 5007, Université Claude Bernard Lyon1-CPE-bat., \\ Villeurbanne Cédex, France \\ Email: ${ }^{*}$ ouobakahonore@yahoo.fr
}

How to cite this paper: Ouoba, K.H. Zougmore, F. and Desmorieux, H. (2018) Effect of Initial Size and Shape Importance on Masse Transfer during Convective Drying. Food and Nutrition Sciences, 9, 1514-1524. https://doi.org/10.4236/fns.2018.912109

Received: November 20, 2018

Accepted: December 26, 2018

Published: December 29, 2018

Copyright (C) 2018 by authors and Scientific Research Publishing Inc. This work is licensed under the Creative Commons Attribution International License (CC BY 4.0).

http://creativecommons.org/licenses/by/4.0/

\begin{abstract}
In this paper the influence of sample initial size on their convective drying at $80^{\circ} \mathrm{C}$ using convective dryer is determined. Results prove that initial size must be taken into account when drying process was estimated. This influence is limited by its form of cut. Comparing cubic form and parallelepiped (slice) one; results seem to show that thickness is the most important parameter governing the transfer phenomena during foodstuff convective drying. Three slices with thickness of $0.5 \mathrm{~cm}$ and surface area of 17,82 and $112 \mathrm{~cm}^{2}$ respectively, dry better than cubic sample with $\mathrm{a}=1 \mathrm{~cm}$ or $\mathrm{a}=2 \mathrm{~cm}$ of arrest and having respectively 6 and $24 \mathrm{~cm}^{2}$ of surface area. All things seem to show that initial surface is not only the essential parameter; but also the thickness of the sample must be taken into account. Indeed, all of the samples with equal thickness $(0.5 \mathrm{~cm})$ and different exchange surfaces dry at the same time, about $210 \mathrm{~min}$, comparing with cubic form $1 \mathrm{~cm}$ of arrest and $6 \mathrm{~cm}^{2}$ of surface and drying time of $230 \mathrm{~min}$. A new parameter noted $\mathrm{D}_{\mathrm{c}}$ called characteristic diameter is so considered to bridge the gaps. It is defined to be the diameter of the biggest sphere we can cut into a sample. This parameter is independent of form of the sample, and time increase with characteristic diameter increasing.
\end{abstract}

\section{Keywords}

Initial Size, Characteristic Dimension, Shrinkage, Cut Form, Exchange Surface Area

\section{Introduction}

Foodstuff drying in Sub-Saharan Africa nowadays comes from local know-how 
or is guided by certain technical sheets that do not take into account all the realities existing in the field [1] [2] [3] [4].

Field observations show that treatment on products before drying varies according to the region or country considered or from one dryer to another [5] [6] [7].

In the practice, products are dried in various geometrical forms a non determinate form or shape: There are dried as picked up, whole or crushed products, reduced to powder or cut into a given form.

The large variety of products cutting shapes seems to complicate the appreciation of the finished product quality. This could give us an idea of the samples initial cut shape and size importance on the quality of the finished product.

The FAO site (2000) [8] reports that vegetables are dried whole and if they are larger, they are first sliced in small pieces of 4 to $6 \mathrm{~mm}$ of thick: onions, okra, mango, banana, etc. Specifically, for example, potato is sliced into chips, and yam is cut into slices of about $10 \mathrm{~mm}$ thick [9]. This multitude of cutting and size shapes seems to be ignored in articles concerning the drying of tropical farm products. It is rather studied the influence of external parameters such as drying air temperature, Ahouannou, 2001 [10] for cassava and chilli, Doymaz, 2007 [11], for tomato. Studies on the performance of dryers are often made according to the layout of products in monolayer or multilayer on the trays. Thus, the study realized by Youcef-Ali et al., 2001 [12] permitted to understand that distributing the product on four grids instead of three makes it possible to reduce the pile effects which reduce the air-product exchange surface. However, nothing has been said about the influence of the sample size or shape, cut into slices 3 $\mathrm{mm}$ thick and whose average diameter is $4 \mathrm{~cm}$ fixed by a caliber.

In the literature, the dimensions of the experimental samples are often neglected for kinetic evaluation or are arbitrated data without taking into account the realities on the ground. Some authors take care to fix the size of the samples in order to eliminate the poorly known size factor. L. Villa-Coralle et al., (2010) [13] characterized the drying of Ataulfo mango of dimensions $3 \times 15 \times 40 \mathrm{~mm}$ and of parallelepipedic shape, thus limiting the influence of the initial size. Hantanipour et al., (2007) [14] characterized the drying of six potato varieties set the cylindrical shape, with dimensions $11<\mathrm{D}<13 \mathrm{~mm}$ for diameters and $45<\mathrm{L}<65$ $\mathrm{mm}$ for height, likewise May and Perré, 2002 [15] took care to fix the shape and the dimensions of the samples by studying the influence of the contraction on the drying flows. Perré and May, 2007 [16] found that the heat transfer coefficient of the potato depended on the shape but also the initial dimensions.

The main goal about this work is to know if the shape and the size of the cutting intervene during the evaluation of the drying of farm products.

For this purpose, we propose to use a product with a homogeneous macrostructure, the sweet potato, which is easy to cut and which will allow us to obtain relatively large sizes.

The shapes studied are cubic and parallelepipedic while covering a wide range of dimensions from 0.5 to $7 \mathrm{~cm}$ thick, according to the sizes encountered in the field. 
In this work we will examine the behavior of the drying kinetics, the normalized fluxes by the surface for various sizes to better understand the influence of these two parameters on drying. Finally, we will look for a dimension that best characterizes drying, which we will call a characteristic diameter.

\section{Material and Method}

\subsection{Sample Preparation}

Sweet potato (Ipomoea batatas) is a root of a creeping plant. It is a tubercle of more or less elongated shape, even rounded, with thin skin. Depending on the variety, the skin color ranges from white to yellow and from orange to purple. The tuber is very rich in starch and sweet taste. The tubers that were used as samples for our experiments, grown in Bobo-Dioulasso (Burkina Faso) were bought in a local market in the same batch pile to reduce the gaps properties of the material. The potato is transported to the Polytechnic University of Bobo-Dioulasso. The tubers are washed, peeled and cut manually according to the desired shape and size with a stainless knife. This accuracy is important to prevent oxidation of surfaces in contact with air oxygen. The cut samples are rapidly immersed in water to prevent oxidation and remove the excess surface starch which forms a film curbing transfers.

\subsection{Drying}

Washed and wiped with blotting paper, the samples are introduced into the oven, the temperature of which is suitably adjusted for drying. We used an AIR concept, temperature ranging from $40^{\circ} \mathrm{C}$ to $250^{\circ} \mathrm{C}$, with digital display of GERME \& TI, in Burkina Faso. The samples are regularly removed for the mass measurement during the drying time and reintroduced in the oven. The mass is determined by a scale (SARTORIUS, $0.001 \mathrm{~g}$ of precision, France). The measurement time is fast so as not to disturb the thermodynamic equilibrium. Given the regular withdrawal of the samples, we consider that the transfers take place on all sides. The samples are directly deposited on the trays. We calculate the initial surfaces as the total area of the sample from the dimensions measured with a Mitutoyo (Japan) micrometer $2 \times 10^{-5} \mathrm{~mm}$. Note that we were unable to measure air velocity and relative humidity, which are important parameters in the evaluation of drying. For this we compare the results of the experiments that were carried out simultaneously and in the same oven to circumvent the influence of these two parameters.

The determination of the dry mass is made by reintroducing samples in the oven at $70^{\circ} \mathrm{C}$ during 24 hours. [16] [17] [18] (AOAC, 1990; Ouoba 2013, ouoba and al. 2014).

\section{Data Exploitation}

\subsection{Water Content}

The initial water content of the product is the quotient of the total mass of water 
contained in the freshly cut product $m_{e}$, divided by the mass of solid material $m_{s^{*}}$

$$
X_{0}=\frac{m_{e}}{m_{s}}=\frac{m_{0}-m_{s}}{m_{s}}
$$

where $m_{0}$ and $m_{s}$ are the initial mass and the dry mass of the sample respectively.

Curves of moisture content as a function of drying time were plotted from the experimental data. From the mass of the sample at time $t$, we deduce the water content according to:

$$
X(t)=\frac{m(t)-m_{s}}{m_{s}}
$$

where $m(t)$ the mass of the sample at any drying time $t$.

\subsection{Drying Kinetics}

From the value of the mass at any time $t, m(t)$ and the dry mass $m_{s}$ of the sample we calculate the water content $X(t)$ according to equation Equation (2). The plot of $X(t)$ versus $t$ gives us the drying kinetics. To have the same basis of comparison, we normalize the water content at any time $t$ by the initial water content $X_{0}$ of the product determined according to Equation Equation (1). What gives us the curves $X / X_{0}-t$.

For the establishment of drying rates, is considered being equal to the difference in water content at time $t-1$ and the water content at time $t+1$ on the time interval $((t-1)-(t+1))[10]$ :

$$
v(t)=-\frac{\mathrm{d} X}{\mathrm{~d} t}=-\left(\frac{X(t+1)-X(t-1)}{t_{t+1}-t_{t-1}}\right)
$$

Then we smooth the values obtained, with a smoothing number equal to 10 , using a macro in Excel. This relation allows us to obtain the curves of the variation of $v(t)$ versus the ratio $\left(X(t) / X_{0}\right)$.

From Equation (3), we deduce the flux by multiplying $v(t)$ by $m_{s} / S$ where $m_{s}$ is the mass of the solid matrix and $S$ the product air exchange surface. The surface considered as constant and equal to the initial surface $S_{0}$ does not often make it possible to clearly obtain a first phase or the existence of a critical state. In this case, it is preferable to take into account the contraction, considering the surface $S(t)$ at current instant of drying.

$v(t)$ is then normalized by its initial value to obtain the curves of the reduced drying rate $V_{r}$ versus $X / X_{0}$, according to the relation (Equation (4)):

$$
v_{r}(t)=\frac{v(t)}{v_{0}(t=0)}=\frac{\frac{\mathrm{d} X}{\mathrm{~d} t}(t)}{\frac{\mathrm{d} X}{\mathrm{~d} t}(t=0)}
$$

\section{Results and Discussion}

\subsection{Influence of Temperature on Convective Drying of Sweet Potato Cubes}

Figures 1(a)-(c) present the drying rates and the mass flux of the cubic samples 


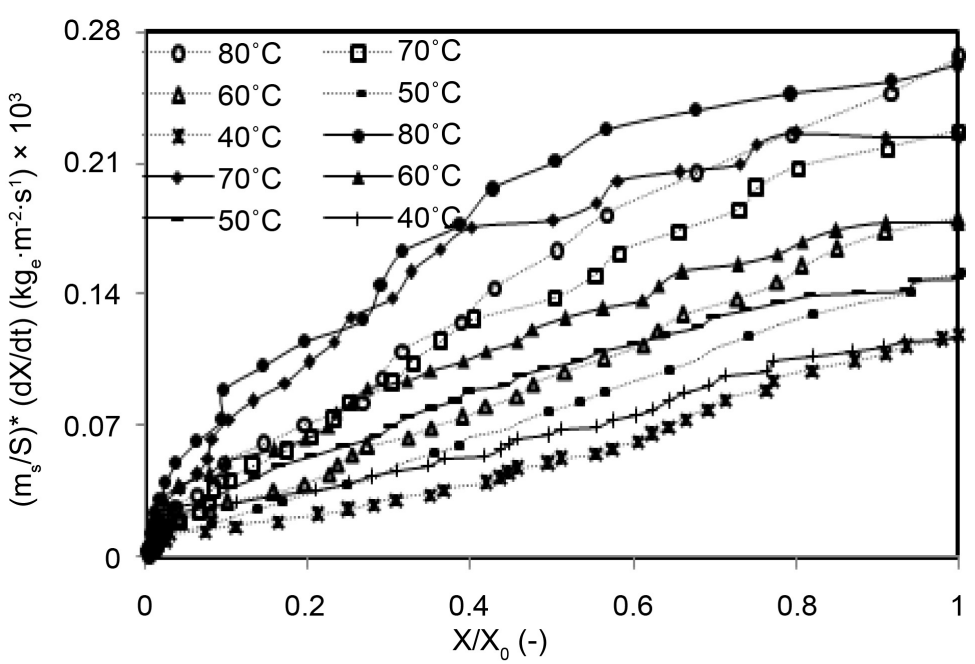

(a)

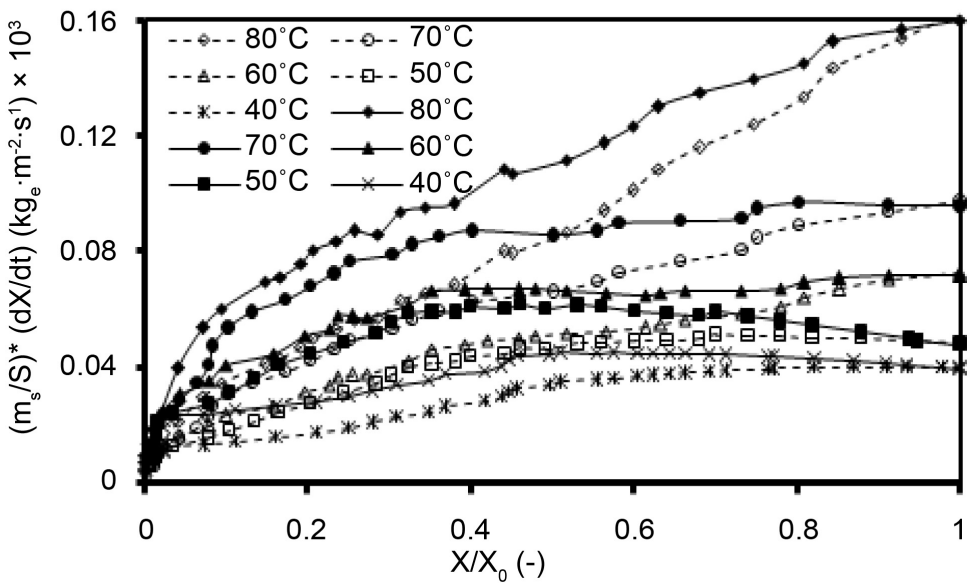

(b)

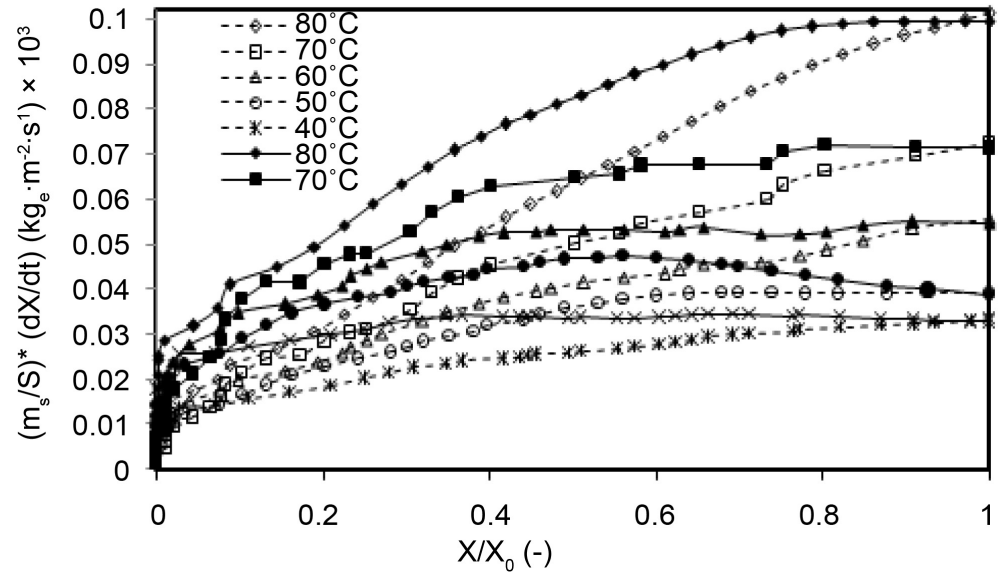

(c)

Figure 1. Influence of temperature on convective drying of cubic samples of sweet potato: (a) $1 \mathrm{~cm}$, (b) $2 \mathrm{~cm}$, (c) $3 \mathrm{~cm}$. Dashed: without taking into account the contraction $\left(S=S_{0}\right)$, solid line: with the contraction $(S=S(t))$.

at 1,2 and $3 \mathrm{~cm}$ edge. The results indicate that external conditions such as temperature influence the drying of farm products. For the drying air temperatures 
of $40^{\circ} \mathrm{C}, 50^{\circ} \mathrm{C}, 60^{\circ} \mathrm{C}, 70^{\circ} \mathrm{C}$ and $80^{\circ} \mathrm{C}$ used, the drying rate is higher for higher temperatures. The initial drying rate as an example for the cubic sample of $1 \mathrm{~cm}$ edge is of the order of $0.011,0.013,0.017,0.020$ and $0.024 \mathrm{~kg}_{\mathrm{e}} \cdot \mathrm{kg}_{\mathrm{ms}}{ }^{-1} \cdot \mathrm{s}^{-1} \mathrm{respec}-$ tively for these samples as shown in Figure 1(a). From these results, it can be concluded that at a given dimension, the flux increases when temperatures increase.

\subsection{Influence of Size on Convective Drying of Sweet Potato Cubes}

In this section, we examine the influence of initial size on drying. The influence of initial size of sweet potato samples was studied at a single temperature of $80^{\circ} \mathrm{C}$. To reduce the influence of the shape parameter, we choose to keep the same shape, cubic for all samples, while varying the size. Samples of cubic shapes and $1 \mathrm{~cm}, 2 \mathrm{~cm}, 3 \mathrm{~cm}, 3.5 \mathrm{~cm}, 4 \mathrm{~cm}$ and $6 \mathrm{~cm}$ of edge were dried under the same conditions $\left(80^{\circ} \mathrm{C}\right)$ : The initial surface of these samples in the same order is 6,24 , 54, 73.5, 96 and $216 \mathrm{~cm}^{2}$. The results in Figure 2 indicate that drying time, considered to be the time taken for the sample from its initial moisture content to $0.1 \mathrm{~kg}_{\mathrm{e}} \cdot \mathrm{kg}_{\mathrm{ms}}{ }^{-1}$, is an increasing function according to dimensions (edges). The drying time is about of $180,340,480,710$ and 760 min respectively for the samples mentioned above.

The influence of the initial size of these cubic samples of 1,2, 3, 3.5, 4 and 6 cmedge respectively, is also visible on the drying flux. Figure 3 shows that the drying flux is higher for small samples. All of the drying rates increase as a function of the water content or decrease as a function of the drying time. Let's note these drying kinetics do not allow us to clearly distinguish a first phase of drying. This lack of constant flux is frequently observed in the case of the drying of farm products. At the initial instant, $X=X_{0}$ the drying rates are $0.0045,0.0055$,

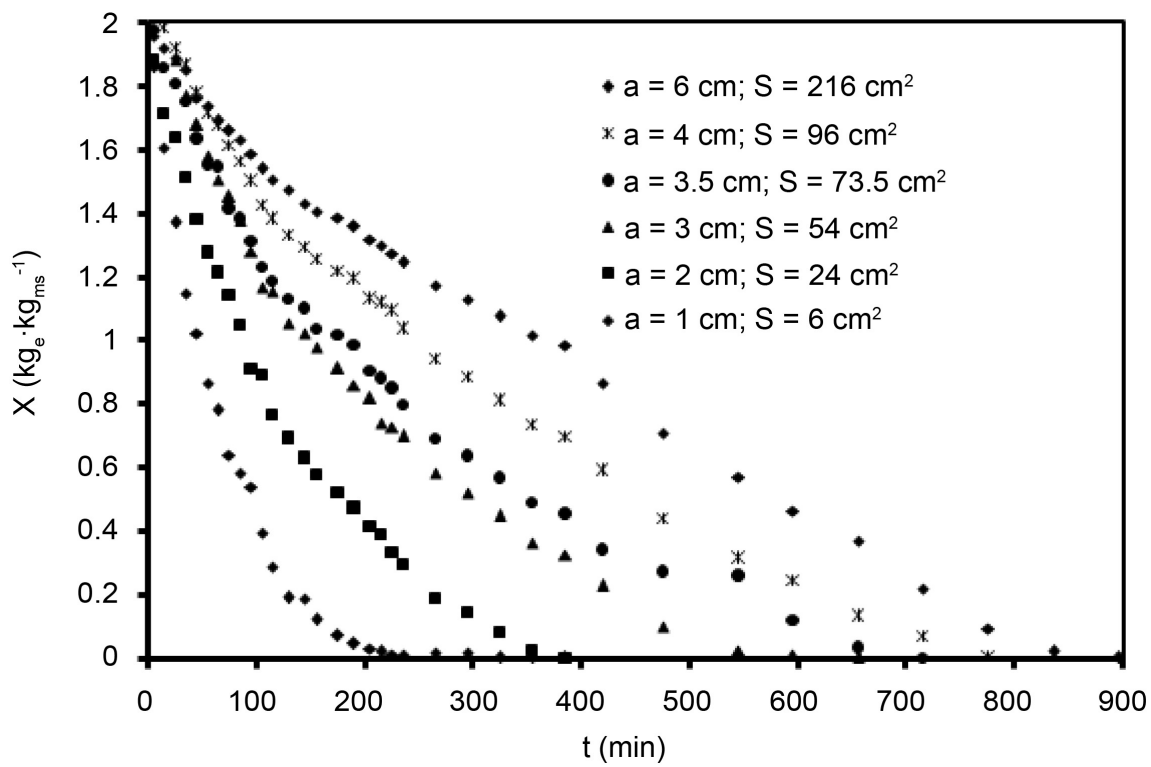

Figure 2. Influence of initial size of cubic sweet potato samples on free convective drying at $80^{\circ} \mathrm{C}$. 


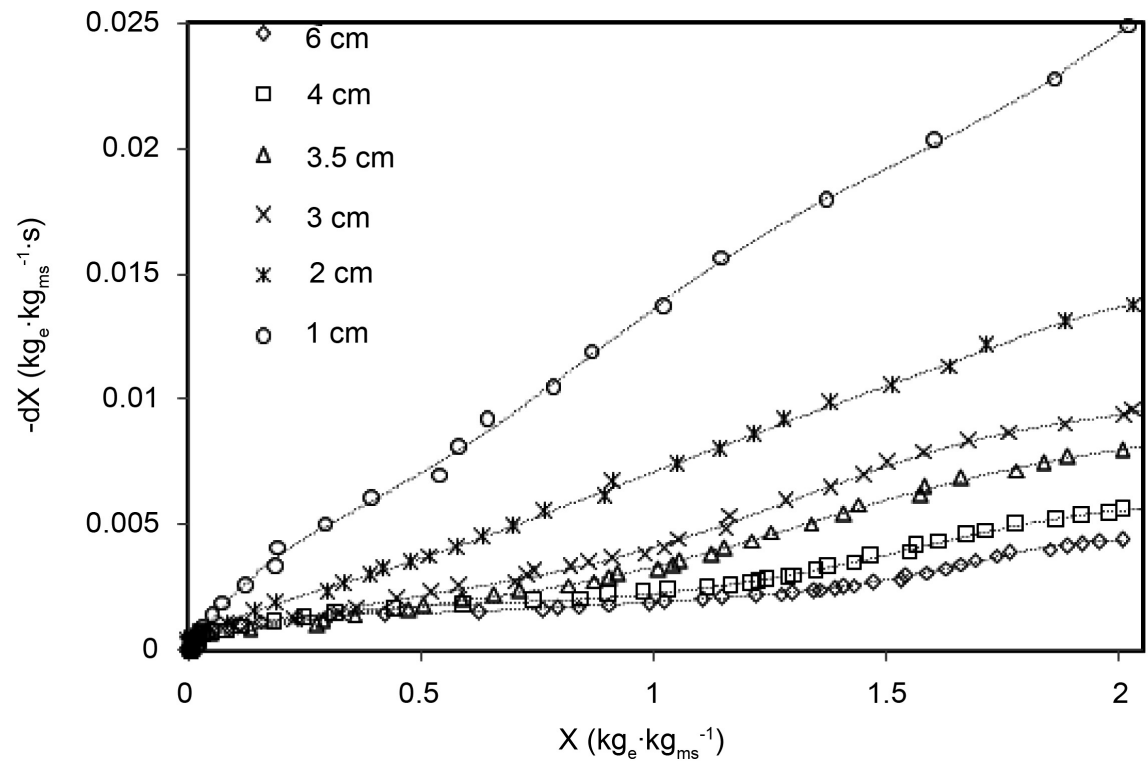

Figure 3. Drying rate for cubic samples of sweet potato at $80^{\circ} \mathrm{C}$, free convection.

$0.0080,0.0095,0.0145$ and $0.0249 \mathrm{~kg}_{\mathrm{e}} \cdot \mathrm{kg}_{\mathrm{ms}}{ }^{-1} \cdot \mathrm{s}^{-1}$ respectively for the cubic samples of $1,2,3,3.5,4$ and $6 \mathrm{cmedges}$. These results indicate that the smaller the sample size is, the faster the drying rate is. It can therefore be concluded that drying is more efficient for small samples as one should expected, as regards the cubic form cut into sweet potato, for this work.

According to the importance of size, we do not have the same curves that characterize drying:

$>$ small samples: Figure 4, which contains the reduced drying flux of small samples, gives quasi-linear curves. It can therefore be concluded that for samples of small sizes, drying is uniform from the beginning to the end of drying. This means that for samples of small size, transfers are almost free and the water of these samples is weakly related. Everything happens as in the case of free evaporation or only in the first phase.

sample with large sizes: the shape of the curves is distinctly different from that of the small sample curves.

One can distinguish three distinct parts delimited by solid lines for the sample of $6 \mathrm{~cm}$ of edge and in dotted lines for the sample of $4 \mathrm{~cm}$ of edge: a first part (1) where the drying flux decreases with a relatively high slope, a second part (2) with a slope slightly negative and a third part (3) where again the slope is high.

\subsection{Importance of S, Thickness and Characteristic Diameter}

The control of the drying would be possible by an identification of a parameter which governs the drying, and which makes it possible to predict the drying time of a product exposed to given drying conditions. In addition, a parameter independent of the sample shape would be useful to the dryers for a quick evaluation of the drying time, especially since most dried products do not have a perfect geometric shape. The exchange surface has an important role in the transfer 


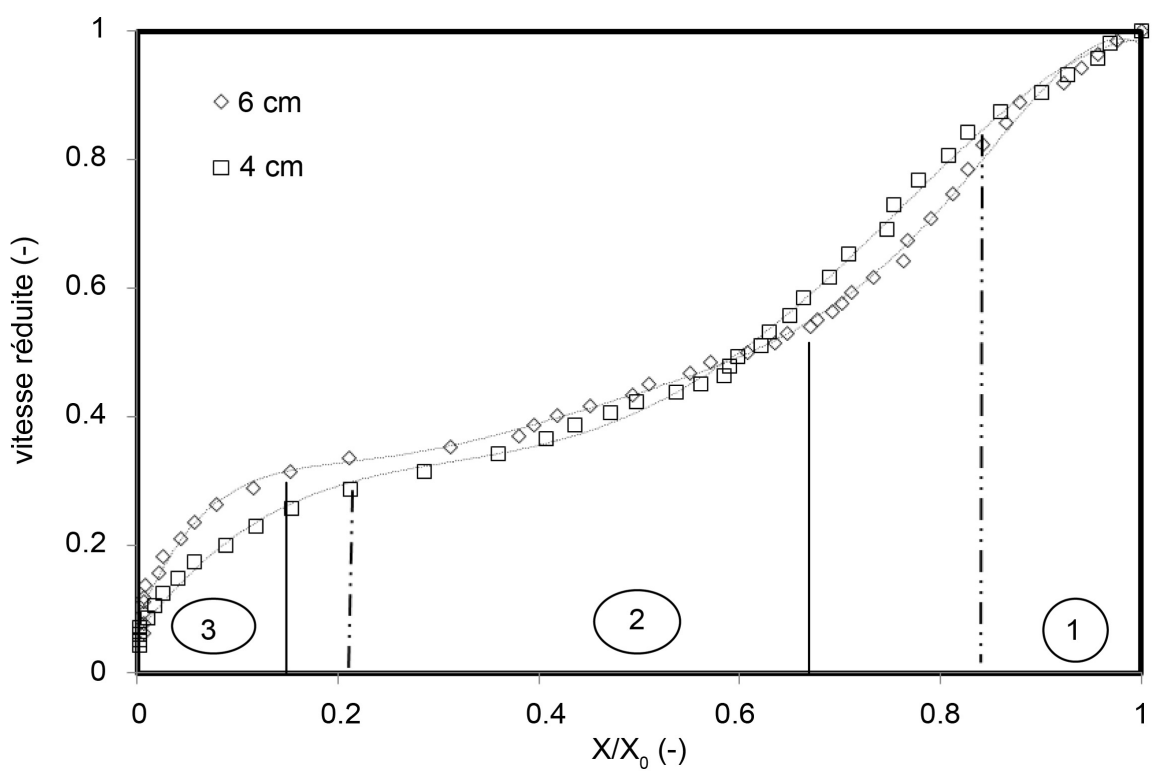

Figure 4. Standard flux curves, cubes of potatoes of 4 and $6 \mathrm{~cm}$ of edges, free convection, $\mathrm{T}=80^{\circ} \mathrm{C}$.

process. Indeed, exchange surface is a boundary between the drying fluid and the system to be dried.

In Table 1, shows that the drying time is increasing as a function of the exchange surface for the identical shapes. But comparing the two forms, we can see that a cube of $6 \mathrm{~cm}^{2}$ of exchange surface takes more time $230 \mathrm{~min}$, than a parallelepiped of 17.82 and $112 \mathrm{~cm}^{2}$ of exchange surface which all both have $210 \mathrm{~min}$ as drying time. On the other hand, this cube has an edge of $1 \mathrm{~cm}$ against $0.5 \mathrm{~cm}$ as thickness for the three parallelepipeds which have taken $210 \mathrm{~min}$ to dry. Then, thickness is the most important parameter for drying process evaluation. By examining the drying with the characteristic diameter, the drying time is an increasing function with Dc. This parameter, which is independent of the shape, therefore governs the drying of wet materials.

In this section, we can clearly propose a parameter that best describes convective drying.

considering the cubic shape, the initial surface, as well as the characteristic diameter seem to be parameters which govern all the drying. Indeed, the drying time Ts is increasing according to these parameters. The larger area of the cubic sample has the longer drying time as long as the volume and the characteristic diameter,

$>$ the parallelepiped shape gives the limit of the importance of the initial surface on the convective drying of farm products. The sample of $46 \mathrm{~cm}^{2}$ of exchange surface dries faster, putting $\mathrm{Ts}=300 \mathrm{~min}$ to dry than the sample of $37.5 \mathrm{~cm}^{2}$ of exchange surface which drying time is $\mathrm{Ts}=350 \mathrm{~min}$.

\section{Conclusions}

In this work, the role of initial size and shape has been studied. It appears that 
Table 1. Influence of dimensions on convective drying of cubic samples of sweet potato at $80^{\circ} \mathrm{C}$ : the initial dimensions or exchange surface.

\begin{tabular}{cccccccc}
\hline Shape & $\mathrm{X}_{0}\left(\mathrm{~kg}_{\mathrm{e}} \cdot \mathrm{kg}_{\mathrm{ms}}{ }^{-1}\right)$ & \multicolumn{2}{c}{ Initial dimensions $(\mathrm{cm})$} & $\mathrm{S}\left(\mathrm{cm}^{2}\right)$ & $\mathrm{Dc}(\mathrm{cm})$ & $\mathrm{Ts}(\mathrm{min})$ \\
\hline Parallelepiped & 1.96 & 0.5 & 2 & 3 & 17 & 0.5 & 210 \\
Parallelepiped & 2.04 & 0.5 & 5 & 7 & 82 & 0.5 & 210 \\
Parallelepiped & 2.05 & 0.5 & 7 & 7 & 112 & 0.5 & 210 \\
Cube & 2.02 & 1 & 1 & 1 & 6 & 1 & 230 \\
Cube & 2.02 & 2 & 2 & 2 & 24 & 2 & 250 \\
Cube & 5.3 & 2.89 & 2.89 & 2.89 & 50 & 2.89 & 380 \\
Cube & 2.12 & 3 & 3 & 3 & 54 & 3 & 570 \\
Cube & 2.76 & 3 & 3 & 3 & 54 & 3 & 580 \\
Cube & 2.44 & 3 & 3 & 3 & 54 & 3 & 600 \\
Cube & 2.03 & 3.5 & 3.5 & 3.5 & 73.5 & 3.5 & 650 \\
Cube & 2.07 & 4 & 4 & 4 & 96 & 4 & 780 \\
Cube & 2 & 6 & 6 & 6 & 216 & 6 & 875 \\
\hline
\end{tabular}

the initial sample size and shape are important parameters to be taken into account to optimize the drying of farm products.

Two forms of cutting, namely parallelepipedic and cubic forms have been studied. For the same amount of wet material, the parallelepiped shape with the smallest possible thickness is the shape that minimizes drying.

The difference in the behavior of these geometrical shapes and size regarding to convective drying process can come from the initial air-product exchange surface, but also from the distance that separates the drying environment from the core of the sample. The importance of the exchange surface comes from the fact that it constitutes the "exit door" of the water in the product. The larger the exchange surface, the more the product loses water. The significant loss of water depending on the exchange surface does not necessarily dictate the drying time. The amount of water contained in the product has an influence on the drying time. The conjugation between the exchange surface and the quantity of water enclosed by this surface can be seen in the geometric form of the cut. In sum, we can deduce that the distance of propagation of heat and mass is the most important parameter. In this present work, we have expressed it in terms of characteristic radius, distance of the last point of the product to be reached by transfers to the exchange surface. From this characteristic radius, we move to the characteristic diameter, more practical, independent of the form, which governs the drying.

\section{Conflicts of Interest}

The authors declare no conflicts of interest regarding the publication of this paper. 


\section{References}

[1] Odile, B.-B. (1991) Etude des effets d'un traitement thermique sur la qualité (flaveur) de quelques plantes aromatiques: Basilic, Ocimum Basilicum L.; Menthe, Menthe Piperita; Persil, Petroselinum Sativum Hoffm; Estragon, Artemesia Dracunculus L.. Thèse de Doctorat, Université de Paris VII.

[2] McMinn, W.A.M. and Magee, T.R.A. (1997) Physical Characteristics of Dehydrated Potatoes-Part I. Journal of Food Engineering, 33, 37-48. https://doi.org/10.1016/S0260-8774(97)00039-3

[3] Prabhanjan, D.G., Ramaswamay, H.S. and Raghavan, G.S.V. (1995) Microwave Assisted Air-Drying of Thin Layer Carrots. Journal of Food Engineering, 25, 283-293. https://doi.org/10.1016/0260-8774(94)00031-4

[4] Rahman, M.S. and Potluri, P.L. (1990) Shrinkage and Density of Squidflesh during Air Drying. Journal of Food Engineering, 12, 133-143. https://doi.org/10.1016/0260-8774(90)90024-3

[5] Nadeau, J.P. and Puiggali, J.R. (1995) Séchage: Des processus physiques aux procédés industriels. Tec \& Doc Lavoisier, Paris.

[6] Rapusas, R.S. and Driscoll, R.H. (1995) The Thin-Layer Characteristics of White Onion Slices. Drying Technology, 13, 1905-1928. https://doi.org/10.1080/07373939508917056

[7] Sablani, S., Rahman, S. and Al-Habsi, N. (2000) Moisture Diffusivity in Foods an Overview. In: Mujumdar, A.S., Ed., Drying Technology in Agriculture and Food Sciences Enfield, 35-59.

[8] FAO (2000) FAO STAT Database Query. Food Agriculture Organization of the United Nations. http://www.fao.org/

[9] FAO (1991) FAO STAT Database Query. Food Agriculture Organization of the United Nations. http://www.fao.org/

[10] Ahouannou, C. (2001) Etude du séchage de produits agroalimentaires tropicaux: Cas du manioc, du piments. Thèse de doctort, Université Nationale de Bénin.

[11] Doymaz, I. (2007) Air-Drying Characteristics of Tomatoes. Journal of Food Engineering, 78, 1291-1297. https://doi.org/10.1016/j.jfoodeng.2005.12.047

[12] Youcef-Ali, S., Messaoudi, H., Desmons, J.Y., Abene, A. and Le Ray, M. (2001) Determination of the Average Coefficient of Internal Moisture Transfer during the Drying of a Thin Bed of Potato Slices. Journal of Food Engineering, 48, 95-101. https://doi.org/10.1016/S0260-8774(00)00123-0

[13] Villa-Corrales, L., Flores-Prieto, J.J., Xamán-Villaseñor, J.P. and García-Hernández, E. (2010) Numerical and Experimental Analysis of Heat and Moisture Transfer during Drying of Ataulfo Mango. Journal of Food Engineering, 98, 198-206. https://doi.org/10.1016/j.jfoodeng.2009.12.026

[14] Hatamipour, M.S. and Mowla, D. (2003) Correlations for Shrinkage, Density and Diffusivity for Drying of Maize and Green Peas in a fluidized Bed with Energy Carrier. Journal of Food Engineering, 59, 221-227. https://doi.org/10.1016/S0260-8774(02)00461-2

[15] May and Perré (2002) The Importance of Considering Exchange Surface Area Reduction to Exhibit a Constant Drying Flux Period in Foodstuffs. Journal of Food Engineering, 54, 271-282. https://doi.org/10.1016/S0260-8774(01)00213-8

[16] Perré, P. and May, B. (2007) The Existence of a First Drying Stage for Potato Proved by Two Independent Methods. Journal of Food Engineering, 78, 1134-1140. 
https://doi.org/10.1016/j.jfoodeng.2005.12.025

[17] Ouoba, K.H. (2013) These of Doctorate. University of Ouagadougou, Burkina Faso.

[18] Ouoba, K.H., Zougmoré, F., Sam, R., Toguyeni, A. and Desmorieux, H. (2014) Characterization of Okra Convective Drying, Influence of Maturity. Food and $\mathrm{Nu}^{-}$ trition Sciences, 5, 590-597. https://doi.org/10.4236/fns.2014.56069 